\title{
University Governance, Radicalism and the Market Economy: Where Student Power Gave Way to Economics and Educative Possibility to the Corporate University
}

\author{
Aidan Cornelius-Bell ${ }^{1}$ \\ ${ }^{1}$ College of Humanities, Arts and Social Sciences, Sturt Road, Bedford Park Flinders University, South \\ Australia, Australia \\ Correspondence: Aidan Cornelius-Bell, Bedford Park Flinders University, South Australia, Australia. \\ Email: aidan.cornelius-bell@flinders.edu.au
}

Doi: $10.23918 / \mathrm{ijsses.v8i2p76}$

\begin{abstract}
This article explores student and staff perspectives on the changes to university governance in a South Australian university. From radicalism, representation, and possibility, through the rapid marketisation of the 1980s and to the distillation of accelerated global capitalism into the managerial veins of university institutions. Using the Flinders University Act a parliamentary tool to incorporate a university as a parallel for the rapid pace of changes made to universities in the country, resulting from Dawkins reforms and more recent Liberal/National Coalition changes to the structure and make up of Australian Higher Education. The article posits that pathway to enabling authentic student, and staff, positions in governance at the highest levels may be a new answer to disconnected student/staff bodies, and a partnering of universities with their communities in a meaningful and authentic way, to work counter capitalism for a united future.
\end{abstract}

Keywords: University, Governance, Capitalism, Government Reforms, Protest, Activism, Student Power

\section{University-Governance Hegemony}

This article explores the perpetuation of university-governance hegemony, from the early depiction of bearded academic fellow, through to contemporary suited CEO-man, and the winding journey to the disestablishment of students and staff in the very act of being a university. In Australia we have always had academic governance which involved 'the public'. At Sydney University this included a religious minister, a politician, or their delegate (Horne et al., 2012). At Melbourne University the council had a relatively even split of academics and 'the public' (Selleck, 2003). Since their origin, Australian universities, from the crumbling sandstone, through the recent monstrosities of glass and steel, have had a 'public' influence. This public influence takes the form of corporate economic interest, with business owners, CEOs, corporate lawyers and economistic thinkers at the helm. In alignment with the general political sentiment of Australia, as a productive colony, whose economy holds centre stage surges into university 'acts' qua the parliamentary

Received: March 24, 2021

Accepted: May 25, 2021

Cornelius-Bell, A. (2021). University Governance, Radicalism and the Market Economy: Where Student Power Gave Way to Economics and Educative Possibility to the Corporate University. International Journal of Social Sciences \& Educational Studies, 8(2), 76-87. 
legislation which incorporates the university, with the state seeing fit to appoint members with business interests. In statement form, this often included a configuration of the words 'demonstrated commitment to educational advancement' two key words in order of ascending importance.

In practice this is (not) enforced by the councils themselves. Historically the 'appointment' of academics was a by-the-academic-community model, or at Oxbridge by-the-church-community model, that involved a senior academic cycling into a leadership position, then out. This formed a collective passing of the baton between old white men with long beards, ensuring continuous control of their institutions - from the upperclass white male hegemon while maintaining a healthy connection to the academic community they served. In what can only be seen as a radical shake up, since the 1990s the make-up of governance structures which appoint vice chancellors have been weighted more towards what this 'public' demands and less towards academic governance, management of academics by academics or democratic structures. Saving value judgements, there is a definite shift in what constitutes governance in Australia's universities. These shifts, with certitude, change the values of what it means to lead a university, and what it means to be, or act as, a university in late modernity. The control of universities originates in hegemonic roots, susceptible to capture by new dominant social groups, but viewing itself as 'outside of politics' (Gramsci, 1996). In this regard, Gramsci termed many old-world institutions' workers "traditional intellectuals", those who saw their role as a public service, separate from political think-tanks, bound to serve the community, as long as the community you spoke about was of the hegemon's liking ${ }^{1}$ (Gramsci, 1996). To current times, where hegemonic ideals are espoused from the top by the Vice-Chancellor CEOs themselves, in a steady eruption of virtues inherited from the populist (re)positioning of capitalist market economics as the singular road to advancing public institutions (Brown, 2015; Harvey, 2005). No longer a university to be 'won over' by the dominant social group, instead led from within by a politician - not by democratic appointment, but on the appointment of a group of legal, corporate, and economistic interests - by the University Council itself.

\section{2. 'Acts' of Governance}

Universities have a multitude of governance mechanisms which serve a variety of purposes. At Flinders University we have a Council, as the peak governance body of the university incorporated by the State in an 'act' of parliament. In this capacity, the University act, through the State, sets forth several inanimate structures and procedures to be followed by appointees and electees of the university infrastructure. An act of setting in motion the university. Upon the act's animation by humans, with particular values, powers, interests and agendas, surface ways of being and doing through governance and through a reciprocal arrangement, these powerfully appointed 'members' ${ }^{2}$ hold a sway over the State, as the State holds over the document form of the University Act. At Flinders, in its original form the University act set out a peak governing body which saw what voices from inside and outside the institution would be valued. At Flinders, the configuration, though somewhat ambiguous, included members of parliament, at least eight academic staff appointed from within, up to six students, some ex officio from elected roles others specifically elected for the positions, and four external, 'public' members (Flinders University Act, 1997;

\footnotetext{
${ }^{1}$ i.e. 'like them' successful, white, male appearing, able bodied, people of relatively wealthy backgrounds.

${ }^{2}$ Purportedly representative of the public, but in recent times mostly CEOs, entrepreneurs, lawyers, economists, and market traders.
} 
Karmel, 1968). These shifts were mirrored both in terms of the learning and teaching interface of the university, and at broader political scales, with a general departure from a broad ranging and critical education, towards a market ready graduate, and from the general public valuing universities as a space for productive ideation to 'capitalist fodder' (Forsyth, 2020). This configuration changed in meaningful ways across the history of the university's act. Momentously, in 1997, the act was changed to remove the members of parliament, and reduce the academic representation from eight to two, increase general representation from one to two and reduce the number of students from five to three. In conjunction with this change, a selection committee was established to appoint the now ten external members under act which could autonomously be selected by the very Chancellor and Vice Chancellor who led the Council. Ostensibly providing control of the appointees to Council to the directors of the Council themselves, with only two overarching but connected conditions: a commitment to higher education, and a value for 'equal opportunity and social justice' (Flinders University Act, 1997, p. 4). The fundamental changes here were amplified in 2017 when the representation of staff and students was reduced to two members and two members respectively (Flinders University Act, 2017, p. 5). These changes mirror shifts to the fundamental fabric of the hegemonic control of universities around Australia. As Marginson and Considine (2000, p. 11) highlight:

Without exception the university leaders in our study saw collegial forms of decisionmaking as an obstacle to managerial rationalities. ... a more recently created democratic tradition in universities, expressed through reforms that created increased staff and student representation on councils and committees ... followed the 'student power' era of the late 1960 s and early 1970s. ... The democratic tradition in governance provided grater space for young academics, students, general staff and women in all categories. ... Nevertheless, along with the collegial tradition, in the present period this democratic tradition is also being pushed aside, and most of its gains are being reversed. (Marginson \& Considine, 2000, p. 11)

Here the undoing of the sentiment of student power in the 1960s and 1970s losing to a managerial trend saw structural reforms and shifts to the constitutional acts of the universities themselves. Rather than valuing academic, student and general staff voice the institutions made way, first, internally for a managerialist agenda, then, through their external influence on governments to modify their founding acts to enforce the hegemonic model of administration through managerialism throughout the institutions (Marginson \& Considine, 2000). This was a marked departure, not only from the academic management of institutions for those institutions - granting that they were almost entirely wealthy, white, and male - but a turn away from the victories of student power movements into a new culture and the emergence of the 'economic rationalist model' into neoliberalism in the university system (Giroux, 2002; Shore, 2010; Sims, 2019). The importance of the changing structures, governance, and associated legislation during the late 1990s and early 2000s cannot be understated. The very possibility for an academic contribution to be made to senior university governance, critical or otherwise, a perspective from the culture of the institution, or truly of 'the public' no longer sits at the table. Flinders suffered a minimum of a $37 \%$ reduction in community 'representation' from a possible 14 of 20 seats to just 5 of 15 , generously including the head of academic senate as an academically aligned senior leader (Flinders University Act, 1997; Flinders University Act, 2017). 


\section{Student Power and the Administration}

Governance conversations, then, take a turn from the late 1990s until the late 2010s from being about the work of the university to a conversation about performance, appearance, and position in the 'education market' (Ball, 2012; Batabyal, 2006; Slaughter \& Leslie, 1997). It is important to note that during this time, globally, students were not silent about the changes occurring in universities. While many 'golden age' discussions of notable decline of universities in a hyper-capitalist, claustropolitan era linger over the momentous victories of student power movements, the vocal activism of students has continued across several modes (Brabazon, 2021). Indeed, student activism of the 1960s in Australia was not necessarily always about student power in the institutions:

The moratorium movement was driven too by the philosophy department then, which was a hotbed of angst and all kinds of things. Professor Brian Medlin was a prime mover in the moratorium campaign and there were several lecturers within the philosophy department who formed the thing called the 'Worker-Student Alliance', and they had trade union connections within the car industry basically. And they were right out there. When they attended moratorium marches, against the law, one of their ambitions was to assault police. Basically, what they did, and if we had political rallies here in the hall and talked about things they would, generally speaking, feel quite relaxed about beating up people who disagreed with them. (Huberto $\left.{ }^{3}\right)$

The institutional politics, brought in part by students, in part by academics, as a confluence of cultural struggles and a university as a facilitator of relative enlightenment was a space of significant dissent, consciousness and pushing boundaries. Between physical violence and illegitimate printing, the university landscape of the 1960s, 1970s and today are drastically different. As Huberto recounted:

At one stage, the SRC [student representative council], were printing off copies of graduation parchments - and were they looked absolutely correct and, you know, well, the inference was clearly the value of your graduation process - this is as it should be. There wasn't even a disclaimer. (Huberto)

This era faced its own challenges, and while it is remembered fondly in traditional Marxist imaginings and student publications, there was a current which came to light late in the 1970s which heralded the end of the radical student-staff partnership, and the allegiance around workers' rights. The movement, which had every right to 'shake up' the university sector, and continues as a strong political force today, the second wave Feminist movement:

I think there were also things about the university culture that that were reprehensible even then. I mean some of the academics, for example, became far too engaged with students in a variety of ways that I thought were less than ethical. I think the whole feminist movement slowed all that down. I mean, that was that was the other side of politics. It's clear that international feminism focussed people's attention on sexual assault, on domestic violence on child abuse, no doubt. And that was that was beyond challenge here even in the mid-

${ }^{3}$ All semi-structured qualitative interview participants have been pseudonymised throughout. 
70s that was in full flight. So, there was there was more than just political politics. No, there was all the other important rights movements as well. $\quad$ (Huberto)

Cultural changes, including movement towards acceptance of feminist demands for equality were, perhaps unremarkably, mirrored in the University act - both in its response, and in amendment to the legislature. Naturally, this lagged significantly behind the necessary demands of the 1970s and 1980s, arriving towards the end of the 1990s with the fifth amendment made to the act stating: "the appointing authority must recognise that the Council is, as far as practicable, to be constituted of equal numbers of men and women" (Flinders University Act, 1997, p. 4). In the same period, following the Dawkins reforms, the number of women in higher education in Australia rose drastically to over $54 \%$ of the bodies present in institutions nationally in 1998 (Marginson \& Considine, 2000). Yet, the governance landscape continued to close to a plurality of perspectives, edging closer to a single model of top-down governance, suspicious of its own origins and with an agenda which positioned the university towards the global economy, not its originary educational ends. In echoes of student power movements, the anti-deregulation and fee increase arguments against the 2010s Liberal National Coalition government's Christopher Pyne saw massive student resistance in protest activism to what threatened, in some instances, to cost students $14 \%$ more per topic taken with some degrees costing students upwards of \$40,000 (Briton, 2014; Gough, 2014). The chant "No cuts! No fees! No corporate universities!" is permanently burned into my mind as a 2014-15 milestone of student outrage and ultimately a victory for students against fee deregulation. Part of the demands of students across this critical period included a seat at the table, both in national politics, and in their respective universities, to ensure that anti-student moves would not occur.

Following the voluntary student unionism legislation changes of 2005, which saw student 'unions' lose their funding mechanisms and bargaining power with the institutions, the Australian federal political system has enjoyed relatively unchecked autonomy in decision making for, and about, universities without student voices (Rochford, 2006). The demand for students to be included in dialogue has not ended and continues through contemporary campaigns against fee hikes in the humanities (Brett, 2021; Daly \& Lewis, 2020; Norton, 2020) as the recent student response to the 'Job Ready Graduates' package has demonstrated. Though, as explored below, the response was considerably stifled compared to the 2015 movement, partly due to the COVID-19 global pandemic, partly due to lack of Labor Party rejection of the package. Across this recent period, since 2017, changes at Flinders have been substantial. The ebbs and flows of student's voices and echoes of student power have resurfaced, and governance has taken on a new landscape. Particularly with the changes in modality for delivery of topics and education through COVID-19, the way that students interact with academics, with the institution and with the issues facing them has changed.

A student I interviewed for this article had a salient comment on the state of student involvement in governance in the contemporary university setting. As a postgraduate student, he had seen several changes to the way that the university elicited student input into decision making and posed that his college was moving in a positive, authentic, direction with regard to listening to students. The change in the feel for student inclusion in governance has not been echoed in the University Act, but possibilities for students are increasing. 
I think academic governance at Flinders has opened back up, there was a really quiet a long period where there was basically no possibility of students being involved in governance, there was probably some superficial play at students having a say, on certain issues, as long as they're, aligned with the decisions that have already been made, so they were not authentically engaged in governance opportunities. But there has been a bit of a move back to at least having a student presence - I know in my college, we have execs who want to make sure that there are at least two students on every committee, on every working group, and are present whenever big and small decisions are being made about the future of courses, topics, about the future of research, the quality of education, and a whole range of other sort of, I guess, quality assurance measures. So, students are starting to be included in those four, particularly well, at least at least in pairs. So, you know, it's usually some configuration of one undergraduate and one postgraduate, but there are some quite senior forums in our college that are, you know, three undergraduates and two postgraduates, they're, they're getting more diverse. Recently, we've also had a student forum. So, the students are brought together a couple of times a year, to participate in sharing their values, um - probably their thinking about Flinders and the College. And those, those forums, where students are consulted on a range of decisions that are about to be made ideas for things that could be done. And students are asked to authentically give their input into the decisions of the college, which are then filtered back up to the university. I don't know how far back up, they actually go. But at least students are being asked, they're being invited to - to input their ideas. And they're being asked to genuinely contribute to the governance landscape of the College, and you know, hopefully, eventually to the university. (Niall)

Doubts about passing decisions of governance bodies which include students, 'up the chain' raises questions about the general lucidity of discussion in those fora. Indeed, if decisions made in colleges ${ }^{4}$ are ever given governance airtime 'up the chain' it is unlikely that the student input will be particularly acknowledged. At the more senior committee levels student politicians still grapple for the power to make decisions, appoint student members, and whether or not to act on information that they are provided. Deeper issues of party politics plague Student Association decision making an issue which has persisted in student governance since the 1960s. On prompting about the role of student politicians in governance, Niall noted:

Oh yeah, I know that on the more senior committees, it's still predominantly the Student Association, the student politicians that get to say what students, students think and do and feel and are interested in, which I don't really think is representative of the vast student body. But it's a bit there are still students present in those forums. Whether or not they speak up is another question and whether it's politically relevant, or whether their political dictators are saying that they're allowed to speak out on certain issues, you know, that certainly plays into it. I think for those people on those, those student politicians in those

${ }^{4}$ A managerialist collapse of the 'Faculty/School' organisational unit. 
more senior forums, but definitely at college level, we're starting to see more students included and authentically valued for the kinds of contributions that they can make. (Niall)

Another student I interviewed, who was aware of governance opportunities in the university, and had participated in a few niches' governance spaces, including sexual harassment working groups at a university level, spoke to the kind of input the student politicians would make. Importantly, at Flinders, for the last three years our Student Association has been led almost entirely by student members of the left-leaning faction of the Australian Labor Party. In this sense, decisions that go against the national platform of Labor will not be raised. However, populist issues that increase attention to the association garner much support:

like he was trying to do a couple of kind of radical things, but it seemed that the second that he got in-it's like, he had no concept of reality. So, he really - he was winging about things as opposed to actually trying to fix them. He stopped doing any of those meetings [sexual harassment response]. He was like, in lockdown, as though that was what everyone else was doing: 'in a war zone'. And whatever cause he was talking about seems to not be important anymore because we have corona now. I guess like right now, [redacted], is on his parking fees mission. That's appealing to the common student, in that it's like tax. Like we'll get taxes down, if you vote us in. ... I think they [student politicians] dropped the ball. But I think that's just matched to what the university's done, because I would say that the university itself has fallen apart, and no one is driving, it's just gone off the road. And so, it's had an effect that is going to eventually have to have an effect on students. (Odette)

The complexity of the relationship between student politics, student power, and student activism should not be understated in this regard. Student politics, and student politicians, have circled back to a point of owning the controlling interest in the 'student voice' on university governance structures. While the representation is not 'wide open', often limited to just two representatives, these structures at Flinders have been established to allow the Student Council members ex officio positions. These student politicians, who for the last two years have been entirely Labor Party affiliates, control input at the highest levels of governance, and will direct student 'voice' towards alignment with the party's national platform. A win for student politicians, not for the students they purport to represent.

Student politicians don't have access to the normal community and universities are not a normal community. And yes, you can talk about how mature age and a mix of gendered students will make for a diverse student pool - but it's not. It's a bunch of mostly white, split 50/50 gender people that, yes, are probably left leaning, and its people that care about student matters: student debt, parking, affordable living or access to services on campus, right? All they can really appeal to is their audience, their audience are mostly the same age, from the same backgrounds, from the same area. Even the degrees are kind of limited, because we don't offer particular degrees or topics anymore and it really does narrow the field of who is available to vote for you. When you start going, okay, what can I get people to vote for me for it has to be popular issues because you've got this incredibly narrow field. The point is they have to appeal to something in order to get voted in, that simple, and it's not compulsory voting. (Odette) 
While student politicians play for power and balance popularity before making any demands, if they make demands, students who find their way onto committees and working groups who have a genuine issue of representation - or at least 'an axe to grind' sometimes find ways to have their voices heard. Unfortunately, amongst my participants this mechanism was not the governing body itself, but the networks around them. Margie recalled when her biggest wins were made:

(Interviewer:) from those governing bodies or from those, you know, bigger decision makers? Is there an interest in fixing things?

(Margie:) No, not as far as I know, I mean, I've kind of learned rather think systemic wins, that it will work better to have side conversations with people. I'll go to professor so and so and I'll just have a little quiet conversation with them about 'these are of the things that I've observed, could you kind of nudge a little bit?' Then they will send an email to so and so. And then they will respond. But if it's a professor that does it they respond totally differently to when Margie, 'Miss Margie Martinez' who is complete nobody, you know, I'm just a PhD candidate. And they kind of allow that there's a different kind of authority. I kind of think I'm learning to network with a few people. (Margie)

The problem of authority and power are a consistent challenge. Not only were those students I spoke to feeling undervalued, or as though they could not make an impact, but they saw themselves as inferior, not having much to say. While they had small victories in personal networking and advocating for their and others causes at a micro scale, presenting at committees did not herald success, and little support was provided. During my interviews, conversations would often return to the value of having students contribute to governance, decision making and even university politics. The resort to expressions of activism as picket protest, or written word, instead of authentically being given presence to speak out was a central concern. In conversations about what would help students feel heard, some of the following arose:

At the moment, there is an opportunity to maybe use COVID as a doorway because everything is online at the moment, and it won't be forever. Maybe there's an opportunity to say 'listen'. It's the principle of designing for input. A kind of universal design, I suppose. But leverage our moment now to make it right. (Orsa)

There is a real opportunity to actually listen and work with us. And it's going to take work on both sides, right? students can't do this alone. We need academics to work with us to give us a voice for those of us that aren't as confident, who don't speak out or ask the questions. For those of us who don't really know what to ask. There needs to be training, there needs to be support. But I think for academics, and particularly for executive, there needs to be the question asked of what's the value of having the student at the table. Because if we've got good representative structures, maybe we don't need all of that bullshit market research. Maybe we can actually authentically run the institution with the students, or at least give them a meaningful saying, and then maybe the students won't be such a goddamn pain in the ass. Because they've got an actual outlet to work with their institution to make a place that works better for everybody. Not just able bodied middleclass white men. (Niall) 
Opening what exists in our university, beyond just having students present, and moving into a new space where representative structures work, cycle through, expose multiple perspectives, go along with training and payment for work done, draws a hopeful future for the plurality of voices desperately needed in our university systems. Drawing into a conversation about the avenues ahead of students, Dyane raised that student partnership, recent 'students as partners' movements in governance abound our institution (Cornelius-Bell \& Bell, 2020), could actually be, a weak avenue forward and that conversations with students about involvement in strategic and organisational governance could pose as a real future for higher education participation at Flinders:

I think that's a word that's missing in the rhetoric. Educational governance ... I've been involved in many committees and boards. When we look at education, governance, there are some things that you have to, you know, be careful of, because it's a legal entity, but if you if you were to drill down 'governance' into lecture theatres it would look like a very different place. Governance is almost like a better term then partnership. Because that suggests immediately involvement in decision making. And then that's where the difference is made. When I get to say: 'yay', 'nay', how about not just a contribution, but it's actually part of the decision-making structure. That's where I guess, the partnership space falls down a little bit. Partnership suggests a little bit of skipping down the road together, you know, and it's not skipping down the road together, we might fight about something we might have conflict, we should, because that is the point where innovation happens, where someone goes, 'hey, don't you know when every time you present that particular lecture and you do it this way, we don't like $x$ ' and then you can change. So, it's like the UK students, when they go: 'hey, don't change curriculum without letting us know!' (Dyane)

Posing university governance, legislature, and policy as the nexus of radical change in the university sector almost seems silly, particularly as these spaces are seen as completely hegemonically controlled by corporate managers. Even amongst academic staff I interviewed, conversations about where the power lies in the institution became questions of governance - and my interviews included no explicit questions on governance. The power imbalances in the corporate university offer the opportunity to question power in its place, and to exploit it to make a meaningful place for students' perspectives, to make things better for students. Though, with a lack of ownership of governance for any student or staff member, there is a long journey ahead.

I was a bit older and wiser, still a bit naive about the system. But I was much more willing to push back on the academics because I had a bit more experience behind me. So, I felt maybe I was going to stay on a level playing field yet perhaps a bit more on a level playing field because I had worked as a casual academic. I felt that there wasn't that power difference between a tutor and myself. So, I could raise some of these ideas without kind of fear of being put back in my place. (Cthrine)

Cthrine felt strongly about the power dynamic between academics and students, in particular that there would always be a power imbalance but that through working together there is a possibility to build relationships that value diversity, perspectives and act on student input. From the background of having experienced the 'level playing field' she had shifted her perspective on what worked with students and 
had a keen interest in providing space for them to experience this background. Cthrine had two hats, as a recent $\mathrm{PhD}$ graduate and an academic staff member in a large Flinders' College, she had the ability to bridge different experiences and experiment with programmes that created equity for her students, using her experience as a springboard:

I'm now the college representative, the liaison, for that [student representative] program. So, the idea of that is to give students a bit more power to talk about their experience of being students within topics. And then they've also got something similar at the course level. But to have, as much as we don't like to think academics are scary, they are no matter what, there's that power difference. So this opens up just another channel where students can talk to their peers and then those nominated representatives can meet with the topic coordinators - and discuss things about the topic, which, so far, we've seen some fantastic changes - not everywhere. But I think opening up those doors makes it so much easier, just provides more opportunities for students to actually voice any concerns that they're having, or good things as well. (Cthrine)

Initiatives like student representation in every topic pave the way for student's entry into governance structures. In Cthrine's College, students are being more actively included in governance structures, as well as at topic and course level conversations about what they will learn, what they want more, or less of, and what the future of their degrees look like.

\section{Positioning the Future}

These conversations about students' involvement in the structure, content and delivery of their courses has direct lineage to the student power movements of the 1960s (Cockburn, 1969; Cornelius-Bell \& Bell, 2020; Jones, 1969). With real support, students might face the hegemonic might of the governance machinery in universities, speak back against the 'God professors' (Forsyth, 2014) or against the vice chancellor as 'CEO-Dictator' (Bonnell, 2016). There may emerge political pressure enough from the young people and university students, that politicians have no choice but to consider instating perforce onto their university's councils and senates. Alternatively, the might weight of hegemonic market rationalist education, played out through those governance systems, might crush the spirit of contemporary student power and activism, or become an instrument of further political replication through singularly empowering the voices of student politicians. The future remains in the hands of the students and academics who work together to forge new relationships, educate at the grass roots, and build resistance to the destructive, crushing weight of global capitalism.

\section{References}

Ball, S. J. (2012). Performativity, commodification and commitment: An I-spy guide to the neoliberal university. British Journal of Educational Studies, 60(1), 17-28.

Batabyal, A. A. (2006). Shakespeare, Einstein, and the Bottom Line: The Marketing of Higher Education. American Journal of Agricultural Economics, 88(3), 767-768. https://doi.org/10/fdc48c 
Bonnell, A. G. (2016). Democratisation or management and corporate capture? Theses on the governance crisis of Australia's semi-privatised public universities. Australian Universities' Review, The, 58(2), 26-32.

Brabazon, T. (2021). Claustropolitanism, Capitalism and Covid: Un/Popular Culture at the End of the World. International Journal of Social Sciences \& Educational Studies, 8(1), 1-17. https://doi.org/10.23918/ijsses.v8i1p1

Brett, J. (2021, March 1). The bin fire of the humanities. The Monthly. https://www.themonthly.com.au/issue/2021/march/1614517200/judith-brett/bin-firehumanities

Briton, B. (2014, May). No cuts! No fees! No corporate universities! Guardian (Sydney). https://search.informit.org/doi/abs/10.3316/informit.472933260110240

Brown, W. (2015). Undoing the demos: Neoliberalism's stealth revolution (First Edition). Zone Books.

Cockburn, A. (1969). The Gathering Storm: Introduction. In A. Cockburn \& R. Blackburn (Eds.), Student Power: Problems, Diagnosis, Action. Penguin.

Cornelius-Bell, A., \& Bell, P. (2020). Partnership as Student Power: Democracy and governance in a neoliberal university. Radical Teacher, 118(1). https://doi.org/10.5195/rt.2020.797

Daly, A., \& Lewis, P. (2020). The Proposed Job-ready Graduate Package: A misguided arrow missing its target. 23(2), 21.

Forsyth, H. (2014). A History of the Modern Australian University. NewSouth.

Forsyth, H. (2020). From progressive pedagogy to 'capitalist fodder': The new universities in Australia. In Utopian Universities: A global history of the new campuses of the 1960s (pp. 305-322). Bloomsbury Publishing Plc.

Giroux, H. A. (2002). Neoliberalism, Corporate Culture, and the Promise of Higher Education: The University as a Democratic Public Sphere. Harvard Educational Review, 72(4), 425-464. https://doi.org/10/gfk29p

Gough, D. (2014, May 28). PR firm gives fee-fighting university students lesson in spin. The Sydney Morning Herald. https://www.smh.com.au/politics/federal/pr-firm-gives-feefightinguniversity-students-lesson-in-spin-20140528-393ug.html

Flinders University Act, 1966.23-5 1 (1997). https://www.legislation.sa.gov.au/LZ/C/A/FLINDERS\%20UNIVERSITY\%20ACT\%201966/ 1997.02.02/1966.23.PDF

Flinders University Act, 1966.231 (2017). https://www.legislation.sa.gov.au/LZ/C/A/FLINDERS\%20UNIVERSITY\%20ACT\%201966/ CURRENT/1966.23.AUTH.PDF

Gramsci, A. (1996). Selections from the Prison Notebooks. Lawrence and Wishart.

Harvey, D. (2005). A Brief History of Neoliberalism. Oxford University Press.

Horne, J., Sherington, G., \& Campbell, R. (2012). Sydney: The making of a public university. Miegunyah Press.

Jones, G. S. (1969). The Meaning of the Student Revolt. In A Cockburn \& R. Blackburn, Student Power: Problems, Diagnosis, Action. Penguin.

Karmel, P. (1968). Flinders: A case-study of new university development in Australia (J. Lawlor, Ed.; 1st ed., Vol. 15, pp. 127-156). Routledge. https://doi.org/10.4324/9780429448379-6

Marginson, S., \& Considine, M. (2000). The enterprise university: Power, governance and reinvention in Australia. Cambridge University Press.

National Union of Students. (2014). No cuts! No fees! No corporate universities! (Image via NUS) [Association Website]. Welcome to National Union of Students. http://nus.asn.au/en/media

Norton, A. (2020). 3 flaws in Job-Ready Graduates package will add to the turmoil in Australian higher education. The Conversation. http://theconversation.com/3-flaws-in-job-ready-graduatespackage-will-add-to-the-turmoil-in-australian-higher-education-147740 
Rochford, F. (2006). Sausage rolls and sports fields: The debate over voluntary student unionism in Australia. Education and the Law, 18(2-3), 161-176. https://doi.org/10.1080/09539960600919852

Selleck, R. J. W. (2003). The shop: The University of Melbourne 1850 - 1939. Melbourne Univ. Press. Shore, C. (2010). Beyond the multiversity: Neoliberalism and the rise of the schizophrenic university. Social Anthropology, 18(1), 15-29. https://doi.org/10.1111/j.1469-8676.2009.00094.x

Sims, M. (2019). Neoliberalism and new public management in an Australian University. Australian Universities' Review, 16(1).

Slaughter, S., \& Leslie, L. L. (1997). Academic Capitalism: Politics, Policies, and the Entrepreneurial University. Johns Hopkins University Press. 